HLA-B27 positive. In total, 254 (66\%) patients started TNF- $\alpha$ inhibitors and $139(34 \%)$ patients received conventional treatment. Patient characteristics were comparable between both groups, except higher disease activity, more often peripheral arthritis, and worse physical functioning in patients starting TNF$\alpha$ inhibitors. NSAID use and disease activity reduced significantly after starting TNF- $\alpha$ inhibitors and remained low and stable during follow-up. In the conventional treatment group, disease activity was low and NSAID remained stable at all visits. GEE analysis over time showed that NSAID use was significantly associated with disease activity (Table 1). In the TNF- $\alpha$ inhibitor group, a significant association of all NSAID parameters with ASDAS was found: NSAID use yes vs. no, ASAS-NSAID index, index $\geq 10$ vs. $<10$, and index $\geq 90$ vs. $<90$. Comparable results were found for BASDAI and CRP. The association between NSAID use and ASDAS remained significant in the 217 patients who used TNF- $\alpha$ inhibitors more than $80 \%$ of the follow-up time and when analyzing only 12 to 52 weeks of follow-up to exclude the initial effect of TNF- $\alpha$ inhibitors, although the regression coefficients were lower in these last analyses. In the conventional treatment group, a significant but less prominent association of NSAID parameters with ASDAS was found: NSAID use yes vs. no, index $>10$ vs. $<10$, and index $>90$ vs. $<90$. BASDAI was only significantly associated with on demand NSAID use. For CRP, no significant associations with NSAID use were found.

\begin{tabular}{|c|c|c|c|c|c|}
\hline & & $\mathrm{B}(95 \% \mathrm{Cl})$ & P-value & Interval & $\mathbf{n}$ \\
\hline \multicolumn{6}{|l|}{ TNF. a Inhibitors } \\
\hline NSAID use Yes & Complete group & $0.825(0.664 \cdot 0.985)$ & $<0.001$ & 1074 & 251 \\
\hline \multirow[t]{3}{*}{ ASAS-NSAID index } & Complete group & $0.009(0.007-0.012)$ & $<0.001$ & 1073 & 251 \\
\hline & TNF- $a \geq 80 \% *$ & $0.011(0.009-0.013)$ & $<0.001$ & 953 & 214 \\
\hline & 12-52 weeks" & $0.005(0.003-0.007)$ & $<0.001$ & 633 & 246 \\
\hline ASAS-NSAID inde $x \geq 10$ & Complete group & $0.831(0.672-0.990)$ & $<0.001$ & 1073 & 251 \\
\hline ASAS-NSAID inde $x \geq 90$ & Complete group & $0.855(0.682-1.028)$ & $<0.001$ & 1073 & 251 \\
\hline \multicolumn{6}{|l|}{ Conventional treatment } \\
\hline NSAID use Yes & Complete group & $0.250(0.006-0.493)$ & 0.045 & 315 & 131 \\
\hline ASAS-NSAID index & Complete group & $0.002(0.000-0.005)$ & 0.059 & 314 & 131 \\
\hline ASAS-NSAID inde $x \geq 10$ & Complete group & $0.223(0.022-0.425)$ & 0.030 & 314 & 131 \\
\hline ASAS-NSAID inde $x \geq 90$ & Complete group & $0.269(0.038-0.501)$ & 0.023 & 314 & 131 \\
\hline
\end{tabular}

"Subgroup analysis of patients who used TNF-a inhibitors $280 \%$ of the follow up time. "Analysis for 12 to 52 weeks of follow-uF (excluding baseline and 6 weeks).

Conclusions: In this observational cohort of established AS patients, NSAID use over time was significantly associated with ASDAS, which was most pronounced for patients treated with TNF- $\alpha$ inhibitors.

Acknowledgements: The GLAS cohort was supported by an unrestricted grant from Pfizer. Pfizer had no role in the design, conduct, interpretation, or publication of this study.

Disclosure of Interest: None declared

DOI: 10.1136/annrheumdis-2017-eular.1971

\section{SAT0417 GRADUAL PROGRESSIVE CHANGE TO EQUAL PREVALENCE OF ANKYLOSING SPONDYLITIS AMONG MALES AND FEMALES IN SWITZERLAND: DATA FROM THE SWISS ANKYLOSING SPONDYLITIS SOCIETY (SVMB)}

H. Baumberger ${ }^{1}, \underline{\text { M.A. Khan }}{ }^{2} .{ }^{1}$ PhD. First president of, Schweizerische Vereinigung Morbus Bechterew, Zurich, Switzerland; ${ }^{2}$ Professor Emeritus of Medicine, Case Western Reserve University, Cleveland $\mathrm{OH}$, United States

Background: Classic ankylosing spondylitis (AS) with radiographic sacroiliitis has long been considered to be more common in men than women. But this difference has gradually decreased with increasing recognition of this condition in women so that the more recent data suggest a range of $2: 1$ to $1.2: 1$ ratio in favor of men [1].
Objectives: To document greater disease recognition in women during the last 30 years in Switzerland as reflected by AS patient membership in the Swiss Ankylosing Spondylitis Society (SVMB) since its foundation in 1978 [2].

Methods: We reviewed the Society's quarterly newsletters that have kept record since 1980 not only of the number of members, but also the percentage of males and females AS patients. We calculated yearly AS patient membership and also change in the male/female patient ratio (M:F).

Results: There has been a progressive decline in the M:F ratios since 1980 as shown in the Figure. There were 44 female forming $28 \%$ of the patient population, with a M:F ratio of 2.57 in 1980 . At the end of 2016, there are 1731 females forming $49 \%$ of the total number of patients, and the M:F ratio is now 1.03

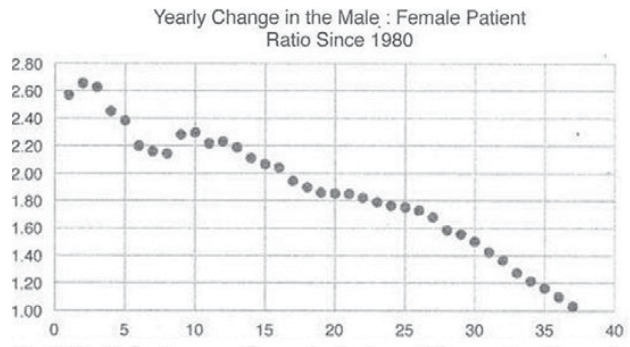

The M:F ratio is shown on the vertical axis, and the number of years is shown on the horizontal axis.

Conclusions: AS is now being recognized as often in females as in males, as reflected in the membership of SVMB over the last 36 years. There can be various reasons for this observation, one of them being the availability of better imaging tools to recognize AS/axial spondyloarthritis (axSpA), especially among women whose disease is clinically and radiologically less pronounced and is therefore often overlooked [2]. For example, the use of MRI (for early detection of spinal inflammation) and the ASAS criteria have resulted in $>50 \%$ females in a German cohort of patients with nonradiographic axSpA [3]. SVMB has played a major role in achieving greater disease recognition in Switzerland by increasing disease awareness and educating patients and their families, the general public, the governing bodies and the allied health professionals about AS, and by interacting closely with rheumatologists. Other possible factors influencing our data include: women outliving men, forming a little greater percentage of the general population, and possibly more likely to join patient self-help groups and societies, We did not investigate any gender difference in disease severity and clinical presentation. In conclusion, AS/axSpA almost equally afflicts men and women in Switzerland.

\section{References:}

[1] Khan MA. Accomplishments of Heinz Baumberger PhD: a remarkable patients with ankylosing spondylitis for 72 years. Clin Rheumatol. 2016;35(6):1637-41.

[2] Khan M.A. Ankylosing Spondylitis - Axial Spondylitis. Professional Communications Inc. 2016. pp. 1-333.

[3] Rudwaleit M, et al. The early disease stage in axial spondylarthritis: results from the German Spondyloarthritis Inception Cohort. Arthritis Rheum. 2009;60:71727.

Disclosure of Interest: None declared

DOI: 10.1136/annrheumdis-2017-eular.3961

\section{SAT0418 ANXIETY AND DEPRESSION ON DISEASE ACTIVITY AND QUALITY OF LIFE OF SPONDYLOARTHRITIS PATIENTS UNDER BIOLOGIC THERAPIES}

N. Madeira ${ }^{1}$, J. Borges $^{1}$, A. Cardoso ${ }^{2}$, L. Miranda ${ }^{1}$, F. Barcelos ${ }^{1}$, C. Miguel $^{1}$, C. Silva ${ }^{1}$, S. Fernandes ${ }^{1}$, R. Trinca ${ }^{3}$, D. Medeiros ${ }^{1}$, R. Campanilho-Marques ${ }^{1}$, H. Santos ${ }^{1}$, R. Leitão ${ }^{1}$, A. Faustino ${ }^{1}$. ${ }^{1}$ Rheumatology; ${ }^{2}$ Nutrition; ${ }^{3}$ Nursering, Instituto Português de Reumatologia, Lisbon, Portugal

Background: Several studies describe an association between anxiety, depression and disease activity in Spondyloarthritis ( $\mathrm{SpA})$.

Abstract SAT0418 - Table 1. Comparison of anxious vs non-anxious and depressive vs non-depressive patients

\begin{tabular}{|c|c|c|c|c|c|c|}
\hline & HADS-A $<8$ & HADS-A $\geq 8$ & $p$-value & HADS-D $<8$ & HADS-D $\geq 8$ & $p$-value \\
\hline Current age, mean $\pm S D$ (years) & $48.9 \pm 11.9$ & $52.6 \pm 10.8$ & 0.045 & $49.2 \pm 11.4$ & $53.2 \pm 11.5$ & 0.072 \\
\hline Age at diagnosis, mean $\pm S D$ (years) & $34.3 \pm 11.9$ & $40.2 \pm 11.5$ & 0.004 & $34.9 \pm 11.5$ & $40.9 \pm 12.5$ & 0.015 \\
\hline Age at 1 st bDMARD, mean $\pm S D$ (years) & $44.0 \pm 11.9$ & $48.7 \pm 10.64$ & 0.013 & $44.7 \pm 11.5$ & $48.7 \pm 11.6$ & 0.059 \\
\hline HADS-A, mean $\pm S D$ & $3.2 \pm 2.1$ & $10.2 \pm 2.1$ & - & $4.5 \pm 3.4$ & $9.7 \pm 3.1$ & $<0.001$ \\
\hline HADS-D, mean $\pm S D$ & $2.9 \pm 3.3$ & $8.3 \pm 2.7$ & $<0.001$ & $2.98 \pm 2.5$ & $10.3 \pm 2.3$ & - \\
\hline ASQoL, mean $\pm S D$ & $3.12 \pm 3.8$ & $10.6 \pm 4.5$ & $<0.001$ & $4.6 \pm 4.7$ & $9.63 \pm 5.8$ & $<0.001$ \\
\hline BASMI, mean $\pm S D$ & $3.1 \pm 1.8$ & $3.9 \pm 1.6$ & 0.003 & $3.2 \pm 1.7$ & $3.9 \pm 1.6$ & 0.016 \\
\hline BASFI, mean $\pm S D$ & $1.7 \pm 1.6$ & $4.1 \pm 2.3$ & $<0.001$ & $2.0 \pm 1.7$ & $4.3 \pm 2.6$ & $<0.001$ \\
\hline BASDAI, mean $\pm S D$ & $1.98 \pm 1.6$ & $4.5 \pm 2.1$ & $<0.001$ & $2.4 \pm 1.9$ & $4.5 \pm 2.3$ & $<0.001$ \\
\hline ASDAS, mean $\pm S D$ & $2.3 \pm 1.3$ & $2.6 \pm 1.1$ & 0.002 & $2.3 \pm 1.2$ & $2.7 \pm 1.2$ & 0.006 \\
\hline Patient's pain assessment (VAS), mean $\pm S D$ & $23.96 \pm 21.8$ & $41.2 \pm 22.1$ & 0.020 & $29.1 \pm 23.3$ & $38.2 \pm 23.0$ & 0.226 \\
\hline Patient's global assessment (VAS), mean \pm SD & $19.1 \pm 19.9$ & $42.8 \pm 23.1$ & $<0.001$ & $22.9 \pm 21.6$ & $42.6 \pm 24.5$ & $<0.001$ \\
\hline physician's global assessment (VAS), mean $\pm S D$ & $10.6 \pm 12.9$ & $20.1 \pm 16.8$ & $<0.001$ & $10.8 \pm 12.4$ & $23.95 \pm 17.8$ & $<0.001$ \\
\hline $\mathrm{TJC}$, mean $\pm \mathrm{SD}$ & $1.4 \pm 4.2$ & $4.3 \pm 9.99$ & 0.002 & $1.79 \pm 5.3$ & $4.45 \pm 10.3$ & 0.002 \\
\hline FACIT-F, mean $\pm S D$ & $42.4 \pm 7.8$ & $29.5 \pm 8.2$ & $<0.001$ & $40.4 \pm 8.6$ & $29.3 \pm 9.5$ & $<0.001$ \\
\hline EQ5D, mean $\pm S D$ & $0.51 \pm 0.11$ & $0.29 \pm 0.19$ & $<0.001$ & $0.48 \pm 0.13$ & $0.28 \pm 0.23$ & $<0.001$ \\
\hline
\end{tabular}


Objectives: To assess disease activity and quality of life in anxious and depressed SpA patients.

Methods: Observational, retrospective, cross-sectional study of SpA patients on bDMARDs, registered at Reuma.pt, Portuguese Rheumatology registry, with $\geq 1$ clinical evaluation from November 2015 to July 2016. Demographic and clinical outcomes including: BASDAI, BASMI, BASFI, ASDAS, DAS 28-3V ESR in peripheral psoriatic arthritis, tender and swollen 44 joints count (TJC, SJC), patients' pain and global assessments, physician's global assessment, CRP, ESR, ASQoL, EQ-5D, FACIT-F for fatigue and HADS scale with 2 domains, HADS-A for anxiety and HADS-D for depression (a cutoff of 8 defining these symptoms), were collected. Statistics: Mann-Whitney test, $p<0.05$. SPSS ${ }^{\circledR}$ v.17.

Results: 160 patients were included, $41.9 \%$ were male, with mean: current age $50.7 \pm 11.9$, age at diagnosis $36.9 \pm 11.96$, at 1 st bDMARD $46.2 \pm 11.8$, time from diagnosis $18.5 \pm 10.3$, years. The mean DAS $28-3 \mathrm{~V}$ ESR was $3.2 \pm 1.4$, BASDAI $2.98 \pm 2.2$, ASDAS 2.4 \pm 1.2 , BASFI 2.68 \pm 2.26 , BASMI 3.36 \pm 1.7 , patient's global assessment $28.8 \pm 24.1$, physician's global assessment 14.5 \pm 15.2 , ESR $18.8 \pm 18.1$ $\mathrm{mm} / \mathrm{h}$, CRP $6.7 \pm 16.01 \mathrm{mg} / \mathrm{L}$, ASQoL 6.2 \pm 5.6 , FACIT-F $37.2 \pm 10.1$ and EQ-5D $0.417 \pm 0.19$. The mean HADS-A was $5.96 \pm 4.01$ and HADS-D was $5.05 \pm 4.1$ (HADS-A $\geq 8$ in $39.5 \%$ and HADS-D $\geq 8$ in $28.3 \%$ patients). Comparison of anxious vs non-anxious and depressive vs non-depressive groups appears on table 1 .

Conclusions: These results suggest that anxious and depressed patients may have higher disease activity, more functional limitations and worse quality of life. These symptoms should not be underestimated, but instead, they should be controlled to achieve clinical improvement.

Disclosure of Interest: None declared

DOI: 10.1136/annrheumdis-2017-eular.5053

\section{SAT0419 SIMILARITIES AND DIFFERENCES BETWEEN HLA B27 POSITIVE AND HLA B27 NEGATIVE SPONDYLOARTHRITIS: RESULTS FROM THE ESPERANZA COHORT}

$\underline{\text { P. Serrano }}^{1,2}$, V. Navarro-Compán ${ }^{2}$, S. Rodríguez ${ }^{3}$, M. Fernández ${ }^{4}$, P. Zarco ${ }^{5}$, E. de Miguel ${ }^{2}$. ${ }^{1}$ Universidad Autónoma; ${ }^{2}$ Hospital la Paz, IdiPaz, Madrid; ${ }^{3}$ Hospital Nuestra Señora de Valme, Sevilla; ${ }^{4}$ Hospital Guadalajara, Guadalajara; ${ }^{5}$ Hospital Fundación Alcorcón, Madrid, Spain

Background: The diagnostic relevance of HLA B27 for spondyloarthritis (SpA) is well established and highlighted by its inclusion in the classification criteria. However, the clinical relevance of this gen on the disease manifestations is unclear.

Objectives: To investigate the influence of HLA B27 status on disease manifestations in patients with recent-onset $\mathrm{SpA}$.

Table 1

\begin{tabular}{|c|c|c|c|c|c|c|}
\hline \multirow[t]{2}{*}{ Characteristic } & \multicolumn{3}{|c|}{ Axial SpA } & \multicolumn{3}{|c|}{ Peripheral SpA } \\
\hline & $\begin{array}{c}\text { HLA-B27+ } \\
\mathrm{N}(\%)=219 \\
(75)\end{array}$ & $\begin{array}{c}\text { HLA-B27- } \\
\mathrm{N}(\%)=72 \\
(25)\end{array}$ & $\overline{p \text { value }}$ & $\begin{array}{c}\text { HLA-B27+ } \\
\mathrm{N}(\%)=28 \\
(33)\end{array}$ & $\begin{array}{c}\text { HLA-B27- } \\
\mathrm{N}(\%)=58 \\
(67)\end{array}$ & $\mathrm{p}$ value \\
\hline Age (years) & $31.4 \pm 7.1$ & $33.8 \pm 6.5$ & 0.01 & $30.6 \pm 8.6$ & $33.9 \pm 7.2$ & 0.07 \\
\hline Male & $151(68.9)$ & $40(55.6)$ & $<0.05$ & $16(57.1)$ & $34(58.6)$ & 0.9 \\
\hline \multicolumn{7}{|l|}{ Symptoms duration } \\
\hline (months) & $12.9 \pm 6.7$ & $13.3 \pm 6.7$ & 0.7 & $8.9 \pm 5.2$ & $9.5 \pm 6.6$ & 0.7 \\
\hline Peripheral arthritis & $44(20.1)$ & $9(12.5)$ & 0.1 & $28(100)$ & $55(94.8)$ & 0.2 \\
\hline Enthesitis & $48(21.9)$ & $9(12.5)$ & 0.08 & $18(64.3)$ & $25(43.1)$ & 0.07 \\
\hline Dactylitis & $13(5.9)$ & $3(4.2)$ & 0.6 & $9(32.1)$ & $19(32.8)$ & 0.9 \\
\hline \multicolumn{7}{|l|}{ EAMs: } \\
\hline - Uveitis & $20(9.1)$ & $3(4.2)$ & 0.2 & $1(3.6)$ & $0(0)$ & NA \\
\hline - Psoriasis & $18(8.2)$ & $15(20.8)$ & $<0.01$ & $2(7.1)$ & $26(44.8)$ & $<0.001$ \\
\hline$-\mathrm{IBD}$ & $4(1.8)$ & $5(6.9)$ & $<0.05$ & $2(7.1)$ & $8(13.8)$ & 0.4 \\
\hline \multicolumn{7}{|l|}{ Diarrhea, cervicitis, } \\
\hline Inflammatory back pain & $\begin{array}{c}9(4.1) \\
83(37.9)\end{array}$ & $\begin{array}{c}2(2.8) \\
29(40.3)\end{array}$ & $\begin{array}{l}0.6 \\
0.7\end{array}$ & $3(10.7)$ & $2(3.4)$ & 0.2 \\
\hline Family history & $84(38.4)$ & $17(23.6)$ & $<0.05$ & $10(35.7)$ & $21(36.2)$ & 0.9 \\
\hline \multicolumn{7}{|l|}{ APRs: } \\
\hline - ESR $(\mathrm{mmHg})$ & $13.6 \pm 13.2$ & $13.5 \pm 14.3$ & 0.9 & $13.8 \pm 14.6$ & $14.2 \pm 12.9$ & 0.9 \\
\hline$-\mathrm{CRP}(\mathrm{mg} / \mathrm{L})$ & $11.3 \pm 15.3$ & $9.4 \pm 14.9$ & 0.4 & $19.5 \pm 48.0$ & $11.0 \pm 18.8$ & 0.2 \\
\hline SJC & $0.3 \pm 1.5$ & $0.2 \pm 0.8$ & 0.8 & $1.6 \pm 3.0$ & $1.3 \pm 2.0$ & 0.6 \\
\hline VAS $(0-10)$ physician & $2.8 \pm 2.2$ & $3.2 \pm 2.1$ & 0.2 & $2.2 \pm 2.2$ & $2.5 \pm 2.2$ & 0.5 \\
\hline VAS $(0-10)$ patient & $4.0 \pm 2.7$ & $4.6 \pm 2.6$ & 0.2 & $2.9 \pm 2.6$ & $3.3 \pm 2.4$ & 0.6 \\
\hline BASDAI & $3.7 \pm 2.3$ & $4.2 \pm 2.2$ & 0.2 & $2.6 \pm 1.7$ & $3.9 \pm 2.4$ & 0.02 \\
\hline BASFI & $2.2 \pm 2.3$ & $2.8 \pm 2.2$ & 0.1 & $1.2 \pm 1.4$ & $1.9 \pm 2.1$ & 0.09 \\
\hline Temporary disability & $19(8.7)$ & $7(9.7)$ & 0.7 & $5(17.9)$ & $13(22.4)$ & 0.7 \\
\hline ASQOL & $5.5 \pm 4.7$ & $7.0 \pm 4.8$ & $<0.05$ & $3.3 \pm 4.0$ & $5.0 \pm 5.3$ & 0.2 \\
\hline
\end{tabular}

Methods: Baseline database from ESPeranza cohort ( $<45$ years, symptoms duration 3-24 months and with inflammatory back pain or asymmetrical arthritis or spinal/joint pain plus $\geq 1 \mathrm{SpA}$ features) was used. Inclusion period in the program was 2008-2011. For this study, 377 fulfilling the ASAS classification criteria for SpA were included. A descriptive analysis was used to compare demographic and clinical characteristics between HLA B27+ and HLA B27patients for both subgroups, axial $\mathrm{SpA}$ and peripheral $\mathrm{SpA}$. Chi- square test for qualitative variables and Student-t test for quantitative variables were employed to compare variables among groups.

Results: A total of 291 patients (75\% B27+ and 25\% B27-) were classified as axial SpA and 86 (33\% B27+ and 67\% B27-) as peripheral SpA. Results (mean -standard deviation- and relative frequencies) are presented in the table. In axial $\mathrm{SpA}, \mathrm{B} 27$ + patients were younger, more frequently males and with a family history of SpA while B27- patients had more frequently psoriasis, IBD and poorer quality of life. In peripheral SpA, B27- had more frequently psoriasis and reported higher BASDAI.

Conclusions: In patients with SpA, HLA B27 status influences on the presentation of the disease. In axial SpA, the presence of B27 is associated with an earlier onset, male predominance and more frequency of family history of SpA. In peripheral SpA, the presence of B27 is linked with lower subjective parameters of disease activity. In both, axial and peripheral SpA, the absence of B27 is associated with psoriasis, IBD and poor quality of life.

Disclosure of Interest: None declared

DOI: 10.1136/annrheumdis-2017-eular.6011

\section{SAT0420 RELATIONSHIP BETWEEN HEALTH-RELATED QUALITY OF LIFE WITH DISEASE ACTIVITY AND FUNCTIONAL STATUS, IN PATIENTS WITH ANKYLOSING SPONDYLITIS}

\section{P. Chiowchanwisawakit, V. Srinonprasert, W. Katchamart. Faculty of Medicine,}

\section{Siriraj Hospital, Mahidol University, Bangkok, Thailand}

Background: Ankylosing spondylitis (AS) is a chronic disease resulting in diminished quality of life $(\mathrm{QoL})$. There was no study regarding QoL in Thai patients with AS.

Objectives: To identify factors associated with quality of life, measured by EuroQol 5-dimension, 5-level questionnaire (EQ-5D-5L), in patients with AS.

Methods: This was a cross-sectional study. Demographic data and outcomes related to health utility or HU [Thai version EQ-5D-5L], disease activity [BASDAI (0-10), ASDAS-ESR or CRP, number of tender (TJC) and swollen joint (SJC), and enthesitis], and functional status [BASFI $(0-10)$ and HAQ (0-3)] were collected. The $\mathrm{HU}$ was calculated on the basis of responses to 5-domains using the Thai value set. Regression analysis was used to explore factors associated with each EQ-5D domain and HU. Multiple models using different outcome measures for disease activity and functional status were performed to identify the best predictive model.

Results: Among 119 AS patients, most (73\%) were male with mean (SD) age of 40.4 (11.6) years. Most (52.9\%) were married and 92 (77.3\%) were employed. The median (IQR) disease duration, BASDAI, BASFI, and HAQ were 7.5 (11.8) years, 3.2 (3.7), 2.3 (4.2), and 0.4 (0.9), respectively. The mean (SD, range) EQ-5D and VAS were $0.75(0.20,-0.24-1.00)$ and $68.8(18.8,10-100)$, respectively. In univariate analysis, higher disease activity, higher functional index score, and more severe peripheral joint involvement were significantly associated with lower $\mathrm{HU}$ and moderate to very severe problem in each EQ-5D domain compared with no to mild problem with $\mathrm{p}<0.05$, except SJC which was not associated with mobility problem. Conversely, age, gender, marital status, and disease duration were not associated with any EQ-5D domains or HU. In multivariate regression analysis, disease activity and functional status were significantly associated with $\mathrm{HU}$ (Table 1), when adjusted for age. The best predictive model using BASDAI, $\mathrm{CRP}$, and $\mathrm{HAQ}$ with adjusted for age correctly predicted $77.4 \%$ of the variance in $\mathrm{HU}$, while using BASFI instead of $\mathrm{HAQ}$ in the same model yielded slightly lower predictive value of $70.7 \%$

Conclusions: Disease activity and functional status were significantly factors related to QoL and HU in patients with AS. To improve QoL, the aim of treatment should be achieve remission or at least low disease activity and improve or at least maintain function.

Disclosure of Interest: P. Chiowchanwisawakit Grant/research support from: Siriraj Research fund, V. Srinonprasert: None declared, W. Katchamart: None declared

DOI: 10.1136/annrheumdis-2017-eular.3155

Abstract SAT0420 - Table 1. Multivariate linear regression analysis of factors associated with the health utility

\begin{tabular}{|c|c|c|c|c|}
\hline Model & Adjusted $\mathrm{R}^{2}$ & Age (yr), Beta $(95 \% \mathrm{Cl})$ & Disease activity, Beta $(95 \% \mathrm{Cl})$ & Functional index, Beta $(95 \% \mathrm{Cl})$ \\
\hline 1 & 0.707 & $0.002(-0.001,0.005)^{\ddagger}$ & $\begin{array}{c}\text { BASDAI: }-0.030(-0.054,-0.006)^{*} \\
\text { CRP: }-0.003(-0.005,-0.002)^{*}\end{array}$ & BASFI: $-0.036(-0.062,-0.011)^{\star}$ \\
\hline 2 & 0.622 & $0.004(0.001,0.007)^{\star}$ & ASDAS-CRP: $-0.049(-0.091,-0.008)^{\star}$ & BASFI: $-0.055(-0.081,-0.029)^{*}$ \\
\hline 3 & 0.592 & $0.003(0.000,0.005)^{\star}$ & ASDAS-ESR: $-0.084(-0.114,-0.054)^{\star}$ & BASFI: $-0.032(-0.049,-0.016)^{*}$ \\
\hline 4 & 0.774 & $0.002(-0.001,0.005)^{\ddagger}$ & $\begin{array}{l}\text { BASDAI: }-0.034(-0.050,-0.017)^{\star} \\
\text { CRP: }-0.002(-0.003,-0.001)^{\star}\end{array}$ & HAQ: $-0.197(-0.270,-0.124)^{\star}$ \\
\hline 5 & 0.722 & $0.003(0.000,0.006)^{\ddagger}$ & ASDAS-CRP: $-0.055(-0.083,-0.026)^{\star}$ & HAQ: $-0.248(-0.319,-0.177)^{\star}$ \\
\hline 6 & 0.695 & $0.003(0.001,0.005)^{\star}$ & ASDAS-ESR: $-0.069(-0.093,-0.046)^{\star}$ & HAQ: $-0.199(-0.250,-0.147)^{\star}$ \\
\hline
\end{tabular}

